\title{
Ultrasonic Guided Waves-Based Monitoring of Rail Head: Laboratory and Field Tests
}

\author{
Piervincenzo Rizzo, ${ }^{1}$ Marcello Cammarata, ${ }^{1,2}$ Ivan Bartoli, ${ }^{3}$ Francesco Lanza di Scalea, ${ }^{3}$ \\ Salvatore Salamone, ${ }^{3}$ Stefano Coccia, ${ }^{3}$ and Robert Phillips ${ }^{3}$ \\ ${ }^{1}$ Department of Civil and Environmental Engineering, University of Pittsburgh, 949 Benedum Hall, 3700 O'Hara Street, \\ Pittsburgh, PA 15261, USA \\ ${ }^{2}$ Department of Structural and Geotechnical Engineering, University of Palermo, Viale delle Scienze, 90128 Palermo, Italy \\ ${ }^{3} \mathrm{NDE}$ and Structural Health Monitoring Laboratory, Department of Structural Engineering, University of California, \\ San Diego 9500 Gilman Drive, M.C. 0085, La Jolla, CA 92093-0085, USA \\ Correspondence should be addressed to Piervincenzo Rizzo, pir3@pitt.edu
}

Received 23 December 2009; Accepted 19 April 2010

Academic Editor: Jinying Zhu

Copyright () 2010 Piervincenzo Rizzo et al. This is an open access article distributed under the Creative Commons Attribution License, which permits unrestricted use, distribution, and reproduction in any medium, provided the original work is properly cited.

\begin{abstract}
Recent train accidents have reaffirmed the need for developing a rail defect detection system more effective than that currently used. One of the most promising techniques in rail inspection is the use of ultrasonic guided waves and noncontact probes. A rail inspection prototype based on these concepts and devoted to the automatic damage detection of defects in rail head is the focus of this paper. The prototype includes an algorithm based on wavelet transform and outlier analysis. The discrete wavelet transform is utilized to denoise ultrasonic signals and to generate a set of relevant damage sensitive data. These data are combined into a damage index vector fed to an unsupervised learning algorithm based on outlier analysis that determines the anomalous conditions of the rail. The first part of the paper shows the prototype in action on a railroad track mock-up built at the University of California, San Diego. The mock-up contained surface and internal defects. The results from three experiments are presented. The importance of feature selection to maximize the sensitivity of the inspection system is demonstrated here. The second part of the paper shows the results of field testing conducted in south east Pennsylvania under the auspices of the U.S. Federal Railroad Administration.
\end{abstract}

\section{Introduction}

Safety statistics data from the US Federal Railroad Administration $[1,2]$ indicate that train accidents caused by track failures including rail, joint bars and anchoring resulted in 2700 derailments and $\$ 441 \mathrm{M}$ in direct costs, during the 1992-2002 decade. The primary cause of these accidents is the 'transverse defect' type that was found responsible for 541 derailments and $\$ 91 \mathrm{M}$ in cost during the same period. Transverse defects are cracks developing in a direction perpendicular to the rail running direction, and include transverse fissures, initiated inside the rail head, and detail fractures, initiated at the head surface as rolling contact fatigue defects.

The most common methods of rail inspection are magnetic induction and contact ultrasonic testing [3-5]. The first method is affected by environmental magnetic noise and it requires a small lift-off distance for the sensors in order to produce adequate sensitivity $[6,7]$. Ultrasonic testing is conventionally performed from the top of the rail head in a pulse-echo configuration. In this system, ultrasonic transducers are located inside a water-filled wheel and are oriented at $0^{\circ}$ from the surface of the rail head to detect horizontal cracks and at $70^{\circ}$ to detect transverse cracks. Such an approach suffers from a limited inspection speed and from drawbacks associated with the requirement of contact between the rail and the inspection wheel. More importantly, horizontal surface damage such as shelling and head checks can prevent the ultrasonic beams from reaching the internal defects resulting in false negative readings. The problem of surface shelling was highlighted in accidents like the ones in Superior, WI (U.S.) in 1991 and Hatfield (UK) in 2000. 
Recently, a testing method based on infrared thermography has been proposed. This method however is challenging due to the optical obscuration caused by the various fittings and fixtures used to hold the rail in place, and to the attenuation produced by contaminants often present on the rail surface [8].

Ultrasonic guided waves (UGWs) are being considered in recent years for rail inspections as an improvement over wheel-type ultrasonic methods [9-18]. In general, UGWs are ideal in those monitoring applications that can benefit from built-in transduction, moderately large inspection ranges, and high sensitivity to small flaws. In rail applications, because these waves propagate along, rather than across the rail, they are ideal for detecting the critical transverse defects. They are also potentially not sensitive to surface shelling because they can run underneath this type of discontinuities. Sometimes when the wavelength of UGWs is in the same order of magnitude of the rail curvature radius, there are referred to as surface guided waves [11]. The frequency range at which the waves are generated typically varies according to the type of ultrasonic source used. The frequency range is important to achieve a penetration depth sufficient to probe the entire rail head cross-section, to allow screening of several meters of rail from a single inspection point, and to reduce the sensitivity to noncritical features.

In the last ten years, techniques that do not require contact between the interrogating (probe) and the interrogated (rail) systems, have been investigated to generate and detect UGWs. Noncontact rail testing has been demonstrated by the use of pulsed lasers and air-coupled transducers $[16,19]$, electro-mechanical acoustic transducers (EMATs) [12, 18, 20], and laser vibrometers [11]. However, the drawback of any noncontact testing when compared to conventional contact testing is a reduced signal-to-noise ratio. The use of signal processing based on the Discrete Wavelet Transform (DWT) helps in overcoming this problem, as recently demonstrated [3, 16, 21-24].

This paper presents a hybrid laser/air-coupled transducer system aimed at detecting defects in the rail head by means of UGWs. The laser is used to generate UGWs in the rail head. Pairs of air-coupled transducers are used to sense the waves propagating along the rail head. The system is coupled to a robust signal processing algorithm devoted to automatic damage detection. The algorithm consists of DWT, feature extraction, and outlier analysis. The DWT is applied to process the raw signals. Relevant statistical data extracted from the recorded signals and after DWTprocessing are employed to construct a uni-dimensional or multidimensional damage index vector. The vector is then fed to an unsupervised algorithm based on outlier analysis.

The novelty of this paper is multifold. First, the outlier analysis is applied to problems associated with the detection of defects in rails. Second, the systematic investigation of feature selection, as an essential tool to maximize the sensitivity of the probing system, is conducted. Then, the attempt to discriminate between surface and internal defects in rail head is carried out by proposing a filtering separation process. The hardware/software/algorithm prototype deployed onto a cart moving on a laboratory rail mock up, represents another

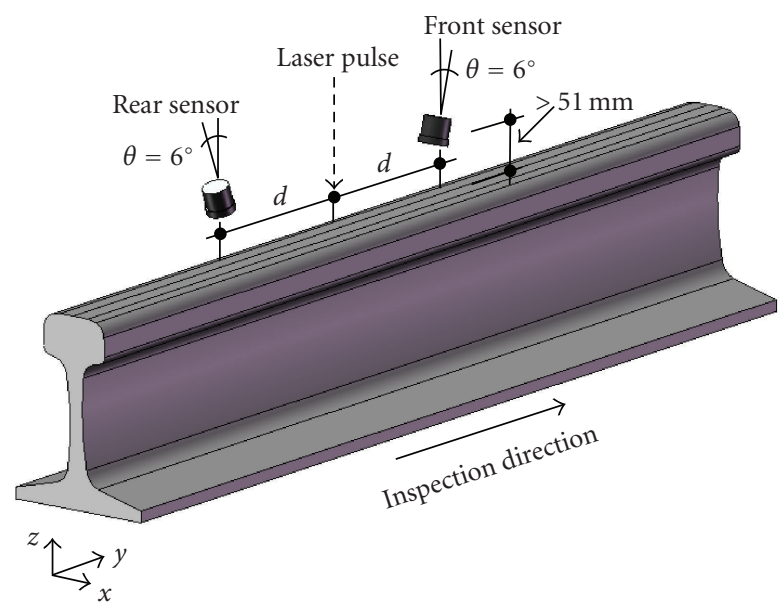

FIGURE 1: Schematic of the sensor pair position with respect to the laser pulse and rail head.

novelty of the present paper. Finally, the results from field testing where part of the inspection algorithm has been implemented are presented.

\section{Laboratory Tests}

2.1. Inspection Prototype. The rail inspection system consisted of a hybrid laser/air-coupled transducers system. A Nd:YAG, Q-switched type, pulsed laser was used to deliver through conventional optics $40 \mathrm{~mm}$-long line beam on the rail head. The line source is known to effectively generate directional and broadband UGWs propagating perpendicular to the line.

Three pairs of air-coupled transducers were used to acquire the ultrasonic signals traveling along the rail head. The three pairs were deployed to provide coverage of the centerline, the gage side, and the field side of the rail head. The sensors were broadband transducers with ultrasonic bandwidth in air $40 \mathrm{kHz}-2.25 \mathrm{MHz}$. As traditionally done with conventional wedge transducers, the alignment angle of the air-coupled detectors was adjusted to maximize the sensitivity to the guided waves, following Snell's law.

The sensors were located at distances larger than $50.8 \mathrm{~mm}$ $\left(2^{\prime \prime}\right)$ from the top of the rail head. Figure 1 shows that the laser was placed in between the sensor pairs. The longitudinal distance $2 d$ between the transducers of the central pair was equal to $343 \mathrm{~mm}$, whereas the distance between the elements of the gage side pair and between the elements of the field side pair was equal to $254 \mathrm{~mm}$. These distances represented a good compromise between high signal-to-noise ratio and high inspection speed. The hybrid system was coupled to a portable PXI unit running under LabVIEW designed to perform laser control and data acquisition. A cart was used to host the hybrid system and the PXI unit.

The ultrasonic signals were acquired at a $5 \mathrm{MHz}$ sampling rate, and successively analyzed using Matlab Wavelet Toolbox. 


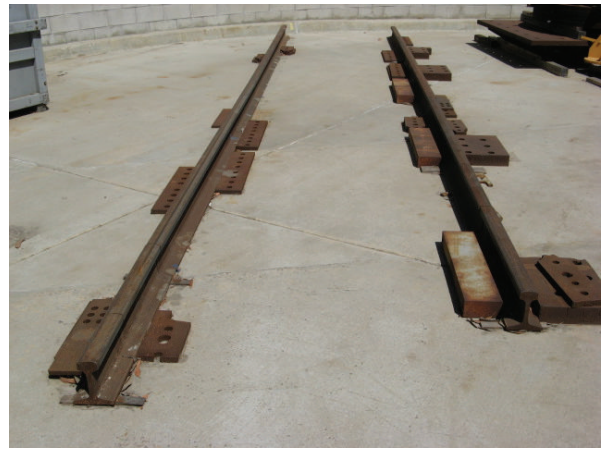

(a)

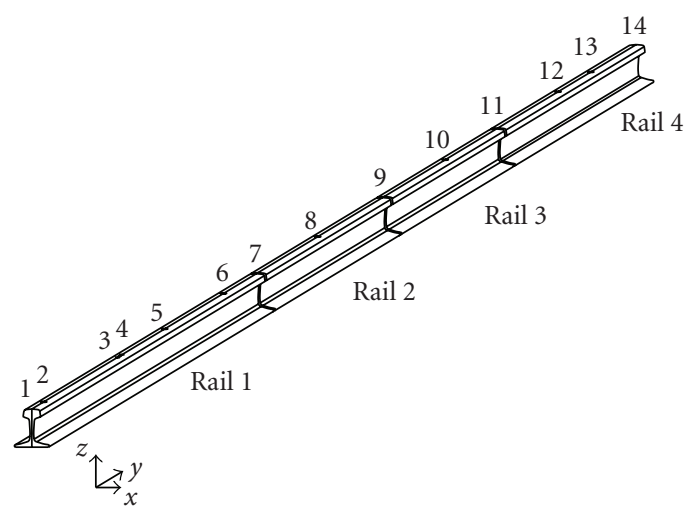

(b)

FIGURE 2: (a) Photo of the rail track mockup at UCSD; (b) layout of the tested mockup. The numbers on top of the rail layout represent the location number listed on the second column of Table 1.

2.2. Experimental Setup and Protocol. The rail-mock up featured approximately a 6 meter long rail track. A photo of such facility is presented in Figure 2(a). The tested segment consisted of four rail sections with surface and internal defects. Rails 1 and 4 were AREMA 110 sections, whereas rails 2 and 3 were AREMA 136 sections. The position of the rail joints and defects are enumerated and shown in Figure 2(b).

Details of the site layout are presented in Table 1. The starting point is identified as location \#1 and it is the joint between a rail that is not drawn in Figure 2(b) and rail 1 . The first rail section contained four surface defects: three transverse defects at locations \#2, \#5, and \#6 and a longitudinal notch over $40 \mathrm{~mm}$ long. The second and third sections contained each an internal defect. These defects were at locations \#8 and \#10.

A hand mapping conducted with a commercial contact ultrasonic instrumentation located the internal defects closer to the gage side of the head. The mapping estimated that they extended over $8 \%$ and $23 \%$ of the cross-sectional head area, respectively. Finally, the fourth section contained an oblique defect oriented at 45 degrees on the $x-z$ plane at location \#12 and a surface transverse defect at position \#13. All surface defects were machined by using an electrical saw.

Three tests were conducted. The cart was manually pushed on the mock-up and an ultrasonic acquisition was made every inch approximately. Each acquisition was enumerated progressively. For instance, during test 1, 78 acquisitions were made and column 5 of Table 2 shows which portion of the rail was probed during each acquisition by the central sensor pair.

Typical waveforms recorded during an acquisition are illustrated in Figure 3. Figures 3(a) and 3(b) present the waveforms recorded from the rear and front central transducers, respectively, when the laser illuminated the rail head at $1150 \mathrm{~mm}$ from the starting point. Ideally, shape and amplitude of the waveforms should be identical; however, slight variations of the sensor's inner sensitivity and alignment, and relative distance between transducers and the beam, produced small differences in the waveforms' amplitudes.
Figures 3(c) and 3(d) show the ultrasonic signals recorded when the laser light impinged on the rail head at $1965 \mathrm{~mm}$. According to Table 1, this acquisition should detect the surface defect machined at location \#6. The fact, that the amplitude of the signal detected by the front sensor is smaller than the signal amplitude from the rear sensor, proves that the laser illuminated a zone between the notch and the rear probe. This is also confirmed by the later pulse of Figure 3(c), which is the result of the reflection from the surface defect. Finally, Figures 3(e) and 3(f) show the ultrasonic signals affected by the presence of the second joint placed between the laser light and the front sensor. No ultrasonic trace is visible in Figure 3(f). The signal detected by the rear sensor, presented in Figure 3(e), shows the stress wave traveling from the laser light, and the echo from the joint.

\section{Signal Processing}

3.1. The Discrete Wavelet Transform. Ultrasonic signals were processed through the DWT, which decomposes the original time-domain signal by computing its correlation with a short-duration wave called the mother wavelet that is flexible in time and in frequency. DWT processing consists of two main parts: decomposition and reconstruction. The decomposition phase transforms the function into wavelet coefficients following hierarchical steps, or levels of different frequency bands. The denoising of the original signal can be achieved if only a few wavelet coefficients, representative of the signal, of one or more levels are retained and the remaining coefficients, related to noise, are discarded. In the reconstruction process, the coefficients pass through reconstruction filters that are closely related but not equal to those of the decomposition [24-27].

3.2. Outlier Analysis. An outlier is a datum that appears inconsistent with a set of data, the baseline that describes the normal condition of the structure under investigation. A set of $p$-dimensional (multivariate) data consists of $n$ observations in $p$ variables. In this study, the detection of 
TABLE 1: Laboratory test site layout.

\begin{tabular}{|c|c|c|c|c|c|c|c|c|c|c|}
\hline \multicolumn{2}{|c|}{ Location \# } & $\begin{array}{c}\text { Distance } \\
(\mathrm{mm})\end{array}$ & Description & $\begin{array}{l}\text { Head area } \\
\text { reduction }\end{array}$ & $\begin{array}{c}\text { Test } 1 \\
\text { center } \\
\text { head pair }\end{array}$ & $\begin{array}{c}\text { Test } 1 \\
\text { gage side } \\
\text { pair }\end{array}$ & $\begin{array}{c}\text { Test } 2 \\
\text { center } \\
\text { head pair }\end{array}$ & $\begin{array}{c}\text { Test } 2 \\
\text { gage side } \\
\text { pair }\end{array}$ & $\begin{array}{c}\text { Test } 3 \\
\text { center } \\
\text { head pair }\end{array}$ & $\begin{array}{c}\text { Test } 3 \text { gage } \\
\text { side pair }\end{array}$ \\
\hline \multirow{11}{*}{ Rail 1} & 1 & 0 & Joint: start of test zone & & $1-4$ & $1-3$ & $1-3$ & $1-2$ & $1-3$ & 1 \\
\hline & \multirow[t]{2}{*}{2} & \multirow[t]{2}{*}{127} & Surface transverse notch & \multirow[t]{5}{*}{$1 \%$} & $5-6$ & $4-5$ & 4 & $3-4$ & $4-5$ & $2-4$ \\
\hline & & & No defect & & $7-11$ & $6-11$ & $5-10$ & $5-10$ & $6-11$ & $5-1$ \\
\hline & 3 & 920 & Start longitudinal notch & & 12 & 12 & 11 & 11 & 12 & 12 \\
\hline & \multirow[t]{2}{*}{4} & \multirow[t]{2}{*}{968} & End longitudinal notch & & 15 & 15 & 15 & 14 & 15 & 15 \\
\hline & & & No defect & & $16-17$ & $16-18$ & 16 & $15-17$ & $16-17$ & $16-18$ \\
\hline & \multirow[t]{2}{*}{5} & \multirow[t]{2}{*}{1428} & Surface transverse notch & \multirow[t]{2}{*}{$16 \%$} & $18-21$ & $19-21$ & $17-20$ & $18-20$ & $18-21$ & $19-21$ \\
\hline & & & No defect & & $22-24$ & $22-25$ & $21-24$ & $21-24$ & $22-25$ & $22-25$ \\
\hline & \multirow[t]{2}{*}{6} & \multirow[t]{2}{*}{2060} & Surface transverse notch & \multirow[t]{3}{*}{$5 \%$} & $25-29$ & $26-29$ & $25-28$ & $25-28$ & $26-29$ & $26-29$ \\
\hline & & & No defect & & - & 30 & - & 29 & - & 30 \\
\hline & 7 & 2432 & Joint & & $30-34$ & $31-33$ & $29-33$ & $30-32$ & $31-34$ & $31-33$ \\
\hline \multirow{4}{*}{ Rail 2} & \multirow{3}{*}{8} & \multirow{3}{*}{3073} & No defect & \multirow{4}{*}{$8 \%$} & $35-38$ & $34-38$ & $34-36$ & $33-37$ & $35-37$ & $34-38$ \\
\hline & & & Internal defect & & $39-41$ & $39-41$ & $37-41$ & $38-40$ & $38-41$ & $39-41$ \\
\hline & & & No defect & & $42-46$ & $42-46$ & $42-46$ & $41-46$ & $42-46$ & $42-47$ \\
\hline & 9 & 3789 & Joint & & $47-50$ & $47-50$ & $47-49$ & $47-49$ & $47-50$ & $48-50$ \\
\hline \multirow{4}{*}{ Rail 3} & \multirow{3}{*}{10} & \multirow{3}{*}{4445} & No defect & \multirow{4}{*}{$23 \%$} & $51-54$ & $51-54$ & $50-52$ & $50-53$ & $51-54$ & $51-55$ \\
\hline & & & Internal defect & & $55-58$ & $55-57$ & $53-56$ & $54-56$ & $55-59$ & $56-58$ \\
\hline & & & No defect & & $59-61$ & $58-61$ & $57-59$ & $57-59$ & $60-61$ & $59-62$ \\
\hline & 11 & 5013 & Joint & & $62-65$ & $62-65$ & $60-63$ & $60-62$ & $62-66$ & $63-65$ \\
\hline \multirow{4}{*}{ Rail 4} & \multirow{3}{*}{12} & \multirow{3}{*}{5657} & No defect & & $66-69$ & $66-70$ & $64-66$ & $63-67$ & $67-68$ & $66-68$ \\
\hline & & & Surface oblique notch & $7 \%$ & $70-73$ & $71-73$ & $67-70$ & $68-69$ & $69-72$ & $69-71$ \\
\hline & & & No defect & & 74 & 74 & - & $70-71$ & - & $72-73$ \\
\hline & 13 & 6010 & Surface transverse notch & $20 \%$ & $75-78$ & $75-78$ & $71-74$ & $72-74$ & $73-77$ & $75-77$ \\
\hline
\end{tabular}

TABLE 2: Mother wavelet, number of largest wavelet coefficients, and statistical features considered in the rail head algorithm monitoring system.

\begin{tabular}{|c|c|c|c|c|c|}
\hline Mother wavelet \# & Mother wavelet & \# & \# of largest coefficients retained ${ }^{(1)}$ & Feature \# & Statistical Feature \\
\hline $\mathrm{a}$ & "db4" & I & $6-6$ & 1 & RMS_o \\
\hline $\mathrm{b}$ & $\mathrm{db}^{\prime}$ & II & $6-10$ & 2 & $\mathrm{ppk}_{-} \mathrm{o}$ \\
\hline c & $\mathrm{db} 10^{\prime}$ & III & $10-6$ & 3 & $\mathrm{CF}_{-} \mathrm{o}$ \\
\hline d & “coif4" & IV & $10-10$ & 4 & $\mathrm{RMS}_{-} \mathrm{w}$ \\
\hline e & “sym5” & & & 5 & ppk_w \\
\hline \multirow[t]{6}{*}{$\mathrm{f}$} & sym7' & & & 6 & $\mathrm{CF}_{-} \mathrm{w}$ \\
\hline & & & & 7 & RMS_r \\
\hline & & & & 8 & $\mathrm{ppk}_{-} \mathrm{r}$ \\
\hline & & & & 9 & $\mathrm{CF}_{-} \mathrm{r}$ \\
\hline & & & & 10 & Area_ FFT \\
\hline & & & & 11 & RMS_FFT \\
\hline
\end{tabular}

${ }^{(1)}$ The first number refers to the decomposition level 2 or 4 when the high-frequency bandwidth or the low-frequency bandwidth is considered, respectively. The second number refers to the decomposition level 3 or 5 when the high-frequency bandwidth or the low-frequency bandwidth is considered, respectively.

outliers is expressed by the Mahalanobis squared distance $D_{\zeta}$, which is a nonnegative scalar defined as

$$
D_{\zeta}=\left(\left\{x_{\zeta}\right\}-\{\bar{x}\}\right)^{T} \cdot[K]^{-1} \cdot\left(\left\{x_{\zeta}\right\}-\{\bar{x}\}\right)
$$

where $\left\{x_{\zeta}\right\}$ is the potential outlier vector, $\{\bar{x}\}$ is the mean vector of the baseline, $[K]$ is the covariance matrix of the baseline and $T$ symbolizes the transpose operation. Both vectors $\left\{x_{\zeta}\right\}$ and $\{\bar{x}\}$ are $p$-dimensional whereas $[K]$ is a square matrix of order $p$.

The mean and the standard deviation can be calculated with or without the potential outlier depending upon whether inclusive or exclusive measures are preferred. In the present study, since the potential outliers are always known a 


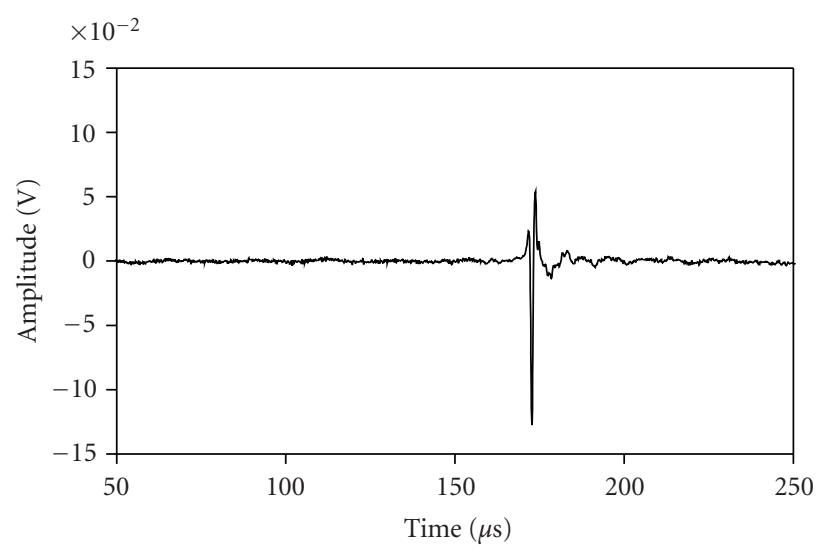

(a)

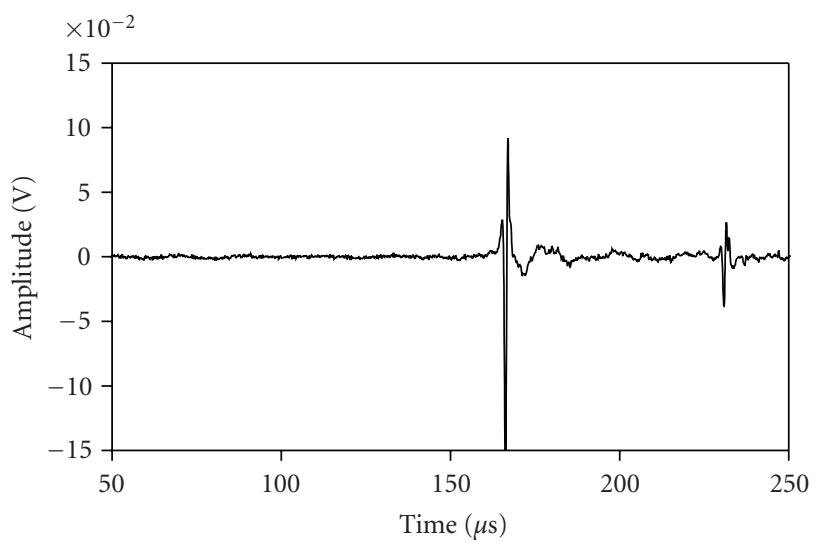

(c)

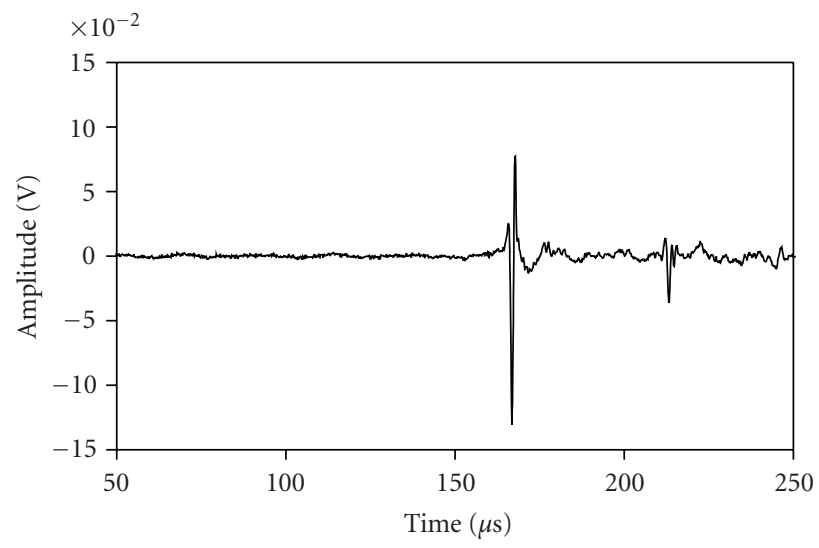

(e)

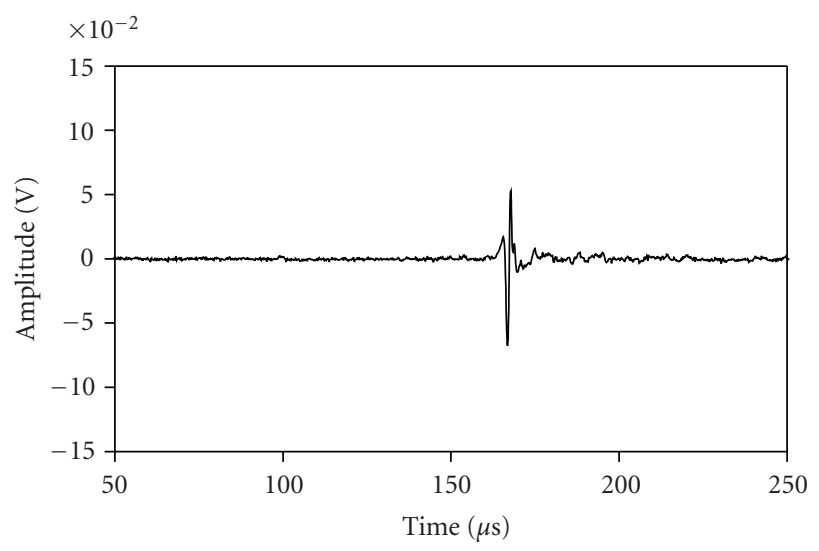

(b)

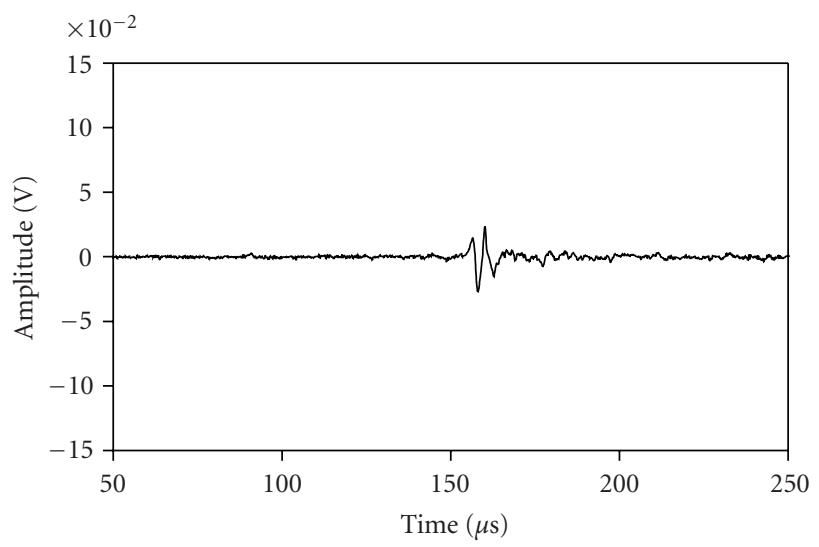

(d)

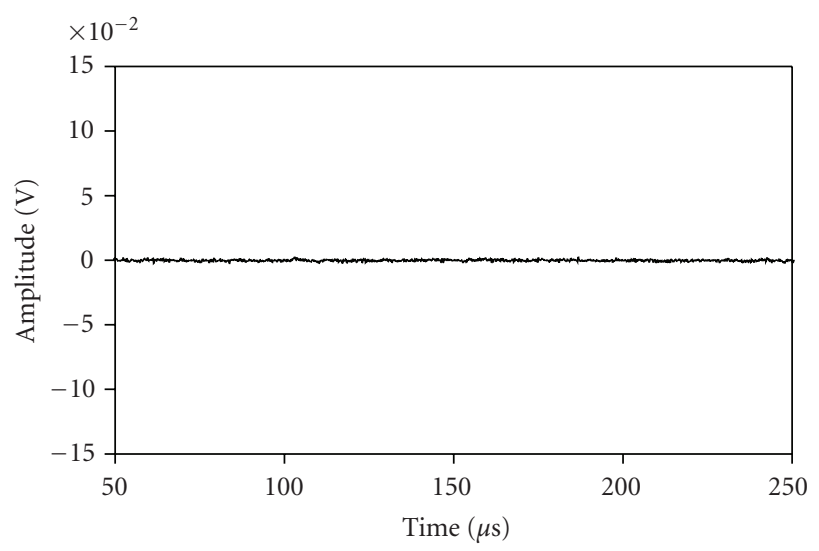

(f)

Figure 3: Typical waveforms detected by the hybrid laser/air-coupled transducer system. Time waveforms detected by the (a) rear and (b) front sensors when the inspection system is probing a pristine rail section. Time waveforms detected by the (c) rear and (d) front sensors when the inspection system is probing a transverse surface notch. Time waveforms detected by the (e) rear and (f) front sensors when the inspection system is probing a joint.

priori, $D_{\zeta}$ is calculated exclusively without contaminating the statistics of the baseline. In order to determine whether a new multidimensional datum is an outlier, the corresponding value of $D_{\zeta}$ has to be compared to a threshold. As the data set consisted of samples generated by adding artificial noise to the ultrasonic signals, once the values of $D_{\zeta}$ of the baseline distribution were determined, the threshold value was taken as the upper value of $3 \sigma$, equal to $99.73 \%$ of the Gaussian confidence limit.

Anytime baseline samples exceed the threshold, they classify as outliers. In the context of the present framework, these values represent false indications of damage, that is, false positives. Conversely, anytime a datum associated with a defect is below the threshold, it is classified as a false negative. 
3.3. Structural Health Monitoring Algorithm. The overall algorithm adopted to the laboratory tests is illustrated in the flowchart of Figure 4. From each ultrasonic measurement other 19 signals were obtained by adding white Gaussian noise. Thus, a total number of 20 samples per acquisition were available. As done in previous works [24, 27, 28] the noise was created by using MATLAB randn function. The statistical features of root mean square (RMS), crest factor (CF), and peak-to-peak (ppk) were computed from these signals. The DWT was applied to every signal. Two wavelet coefficient vectors were created by separating the second and third decomposition levels from the fourth and fifth decomposition levels. The second and the third levels comprise approximately the $300 \mathrm{kHz}-1.2 \mathrm{MHz}$ range. Such a range is hereafter indicated as high-frequency bandwidth. The fourth and fifth levels instead include approximately the $75 \mathrm{kHz}-300 \mathrm{kHz}$ range. This range is hereafter indicated as the low-frequency bandwidth. Owing to their small wavelength, high frequency acoustic signals are expected to be more sensitive to surface defects than internal defects. Each of the two coefficient vectors was threshold by retaining the largest wavelet coefficient moduli.

Denoised signals were obtained by using DWT reconstruction process. The same statistical features introduced above were applied both to the wavelet coefficient vectors and to the denoised signals.

In order to increase the set of features, the Fourier transform of the denoised signals was evaluated, and the area (Area_FFT) and the RMS (RMS_FTT) of the frequency spectrum were calculated.

3.4. Damage Index Vector. Each selected feature was employed to compute a damage index. As the laser light was delivered in the middle between the transducers, the damage index was calculated as the ratio between a certain feature of the signal detected by the front sensor, $F_{\text {front }}$, over the same feature from the rear sensor, $F_{\text {rear }}$. The inverse was computed as well

$$
\text { D.I. } f / r=\frac{F_{\text {front }}}{F_{\text {rear }}}, \quad \text { D.I. } r / f=\frac{F_{\text {rear }}}{F_{\text {front }}} .
$$

Only the largest value between D.I. $f / r$ and D.I. $r / f$ was considered. As such every time a defect was between the laser light and either one of the transducers, the damage index was expected to increase from its ideal value of 1 with increasing defect size. Two or more features were used as the elements of a multidimensional damage index vector, which represented the input of the multivariate analysis. Table 2 summarized the mother wavelets, the number of retained coefficients, and the features considered in the present study.

\section{Experimental Results}

4.1. Features and Frequency Bandwidth Sensitivity. The importance of selecting the appropriate statistical features and frequency bandwidths was investigated. Figure 5 compares the damage indexes associated with the vector of the wavelet coefficients obtained by decomposing the original signals with the db10 mother wavelet. Six coefficients at both levels of each bandwidth were retained. Thus, following the notation introduced in Table 2, the filter combination c_I was used. The indexes are plotted as a function of the acquisition position. The statistical features of RMS, ppk, and CF, were used. For this particular study also the value of the largest coefficient modulus was considered. The results of test 1 are presented. The high frequency bandwidth contained in the signals acquired with the central transducers and the gage side transducers are illustrated in Figures 5(a) and 5 (c), respectively. The results from the analysis of the low frequency components are instead presented in Figures 5(b) and 5(d), respectively. To improve the readability of the plots the vertical axes are scaled down. As expected, the transducer pair deployed on the gage side of the rail is less suitable to identify the presence of anomalies located on the central portion of the rail, but it is effective to unfold the presence of the gage oblique defect. This is demonstrated by the sharp increase of the damage index around acquisition \#71.

In Figure 5(d) a peak at acquisition \#39 is visible when considering the statistical feature of the CF. Such a peak is related to the presence of the first internal defect. This result confirms the diagnostics made by conventional ultrasonic contact probes, that is, that the internal defects were close to the gage side.

4.2. Multivariate Analysis. The purpose of combining features was to increase the sensitivity to the presence of damage. However, the use of all eleven features listed in Table 2 may not be necessary and the selection of all features may degrade the detection performance. To investigate this aspect, a parametric analysis was carried out. All of the features were considered ranging from all combinations of two-dimensional damage index vectors to the single combination of an 11-dimensional vector. Figure 6 shows the Mahalanobis squared distance of the best and worst combination as a function of the sample number. The values are related to the analysis of the high-frequency bandwidth of the ultrasonic signals acquired by the central sensor pair. The horizontal lines in this figure represent the $99.73 \%$ confidence thresholds. The algorithm performance ranged from $93 \%$ to $57 \%$. The criterion used to sort the success rate was the same discussed in Section 4.3 Some false negatives are located in correspondence with the longitudinal and the gage oblique defects. The combination $c_{-} I_{-}(1-3,6,9)$ yielded to the best performance. Such a combination used db10 mother wavelet, the six largest coefficients at both level 2 and 3 and five features. The values of the Mahalanobis squared distance associated with the presence of a defect are several orders of magnitude higher with respect to the threshold. The poor performance of the "worst combination" b_II_(9, 11 ) is noticed by the many false negatives located within the samples associated with the transverse defect.

The same routine was applied to process the waveforms detected by the gage transducer pair. Figures $7(\mathrm{a})$ and $7(\mathrm{~b})$ show the Mahalanobis squared distance as a function of the sample numbers for the high-frequency and low-frequency bandwidths, respectively. For the low frequency component, 


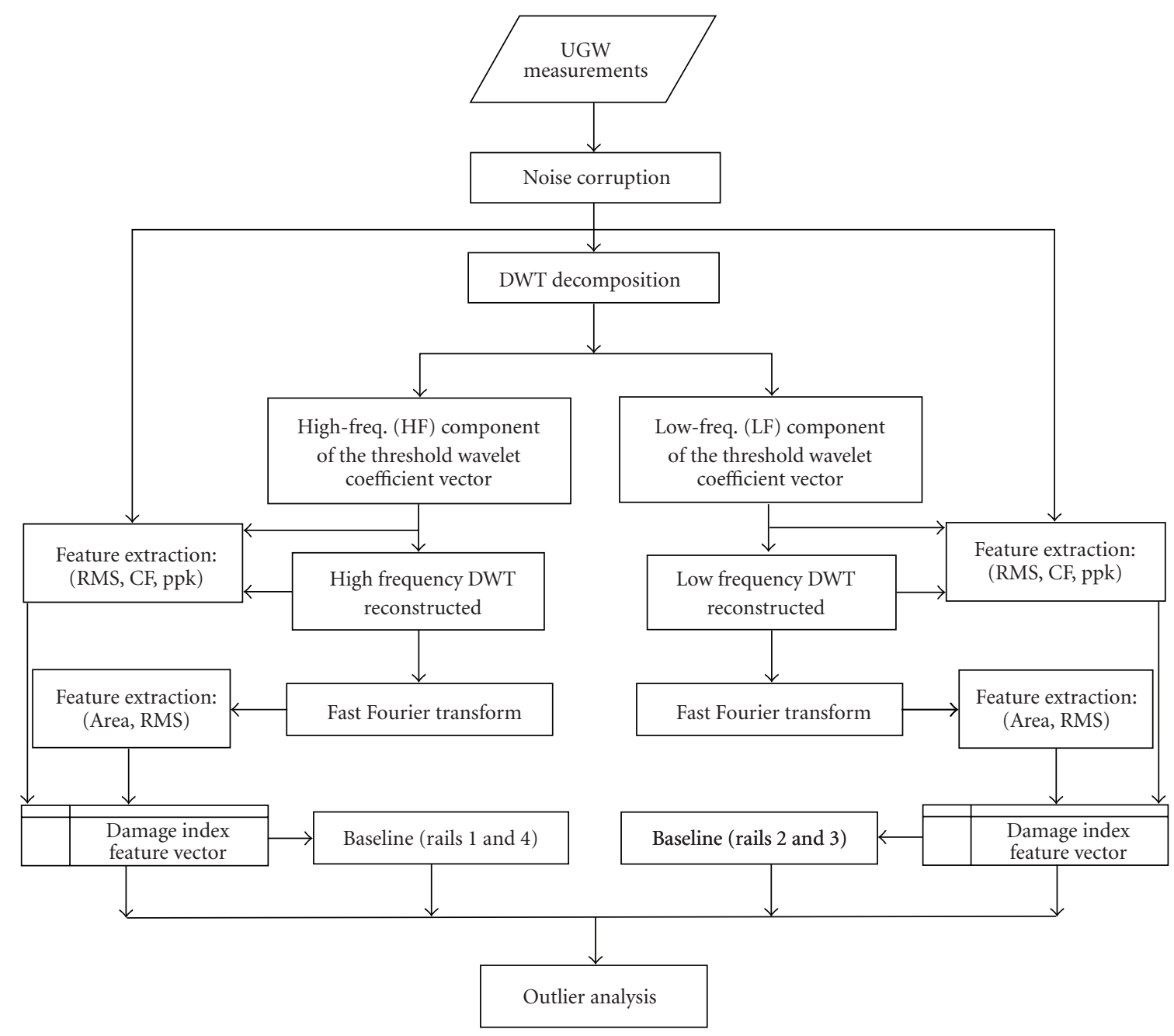

FIGURE 4: Flowchart of the automatic damage detection algorithm based on discrete wavelet transform, feature extraction, and outlier analysis.

the ranking criteria to assess the combination which provides the best algorithm performance were given by the highest percentage of outliers related to the internal defects and the lowest number of false positives.

The best performance was obtained filtering the signals with the coif 4 mother wavelet, retaining 10 and 6 of the largest coefficients at levels 4 and 5, respectively and using ten features. This means the combination d_III_(2-11).

The first internal defect, comprised in the sample range 781-840, was detected by using both bandwidths. The second internal defect, comprised in the sample range 1101-1160, was detected only using the low frequency bandwidth.

The hand mapping revealed that the second internal defect was located more than $10 \mathrm{~mm}$ below the rail head surface, whereas the first internal defect lied underneath the rail surface. Therefore, the latter defect was also detectable exploiting the high-frequency bandwidth of the propagating guided waves. This outcome demonstrates that the proposed algorithm yields to the depth location of internal defects.
Table 3 summarizes the best and worst performances of the two transducer pairs at both frequency bandwidths.

4.3. Repeatability Tests. In order to verify the repeatability of the setup, two more tests were conducted on separate days. Between each test session, the cart hosting the prototype was removed from the rail. Minimal variations of the transducers orientation and alignment of the optical system, if any occurred, were unintended. The outlier analysis conducted on these two tests used the same baseline data of Test 1 . The same level of noise was added to the raw waveforms recorded during Test 2 and Test 3. Figures $8(\mathrm{a})$ and $8(\mathrm{~b})$ show the Mahalanobis squared distance as a function of the sample number for Test 2 and Test 3 , respectively. The results are associated with the high frequency component of the waveforms acquired with the central pair. In Figure 8(a), the results from the features' selection that maximize the detection of the transverse and longitudinal defects in Test 2 and Test 1 are superimposed. Similarly, Figure 8(b) shows 
TABLE 3: Test 1. Multivariate analysis: percentage of outliers for various transducer pairs, frequency bandwidths, and damage types. The best and the worst combination of wavelet processing and damage index features are presented.

\begin{tabular}{|c|c|c|c|c|c|c|}
\hline \multirow[b]{3}{*}{ DATA } & \multirow[b]{3}{*}{ Best/Worst } & \multirow[b]{3}{*}{ Combination } & \multicolumn{4}{|c|}{ Defect type } \\
\hline & & & Transverse & Longitudinal & Oblique & Internal \\
\hline & & & & Succes & & \\
\hline \multirow{2}{*}{$\begin{array}{l}\text { Central sensors } \\
\text { high-freq }\end{array}$} & $\mathrm{B}$ & c_I_ $(1-3,6,9)$ & $92.8 \%$ & $48.8 \%$ & $22.5 \%$ & \\
\hline & $\mathrm{W}$ & b_II_(9,11) & $57.1 \%$ & $0 \%$ & $2.5 \%$ & \\
\hline \multirow{2}{*}{$\begin{array}{l}\text { Central sensors } \\
\text { low-freq }\end{array}$} & $\mathrm{B}$ & a_IV_(1-3,5-11) & $93.2 \%$ & $65 \%$ & $78.8 \%$ & \\
\hline & $\mathrm{W}$ & a_II__(5,9) & $41.8 \%$ & $0 \%$ & $0 \%$ & \\
\hline \multirow{2}{*}{$\begin{array}{l}\text { Gage sensors } \\
\text { high-freq }\end{array}$} & $\mathrm{B}$ & a_II_(1-4,8-9) & $58.1 \%$ & $0 \%$ & $41.7 \%$ & \\
\hline & $\mathrm{W}$ & a_IV_- $(3,5)$ & $23.5 \%$ & $0 \%$ & $5 \%$ & \\
\hline \multirow{2}{*}{$\begin{array}{l}\text { Gage sensors } \\
\text { low-freq }\end{array}$} & $\mathrm{B}$ & a_III_(1-3,5-11) & $70.4 \%$ & $8.8 \%$ & $68.3 \%$ & \\
\hline & $\mathrm{W}$ & a_IV_(3,5) & $33.8 \%$ & $0 \%$ & $13.3 \%$ & \\
\hline \multirow{2}{*}{$\begin{array}{l}\text { Central sensors } \\
\text { high-freq }\end{array}$} & $\mathrm{B}$ & $c_{-} I_{-}(1-2,4-9,11)$ & & & & $57.1 \%$ \\
\hline & $\mathrm{W}$ & b_II_( $(4,5)$ & & & & $0 \%$ \\
\hline \multirow{2}{*}{$\begin{array}{l}\text { Central sensors } \\
\text { low-freq }\end{array}$} & $\mathrm{B}$ & $f_{-} V_{-}(1-3,5-6,8-9,11)$ & & & & $77.9 \%$ \\
\hline & $\mathrm{W}$ & b_I_ $(1,2,10)$ & & & & $0 \%$ \\
\hline \multirow{2}{*}{$\begin{array}{l}\text { Gage sensors } \\
\text { high-freq }\end{array}$} & $\mathrm{B}$ & $\mathrm{f}_{-} \mathrm{I}_{-}(1,4-9)$ & & & & $41.7 \%$ \\
\hline & $\mathrm{W}$ & a_IV_(3,5) & & & & $0 \%$ \\
\hline \multirow{2}{*}{$\begin{array}{l}\text { Gage sensors } \\
\text { low-freq }\end{array}$} & $\mathrm{B}$ & d_III_(2-11) & & & & $60 \%$ \\
\hline & $\mathrm{W}$ & a_IV_(3,5) & & & & $0 \%$ \\
\hline
\end{tabular}

the results from the selections that maximize the detection of the transverse and longitudinal defects in Test 3 and Test 1 . The values of the corresponding thresholds are superimposed. It is evident that the results are very similar. As the number of acquisitions changes, the total number of samples varies. This causes the slight shift between the two plots in Figure 8(a).

4.4. Discussion. Overall it was observed that the percentage of defects properly identified as outliers increases with the increase of the damage index vector dimension, whereas the number of false positives is relatively constant. This outcome is visualized in Figure 9 where the success rate is plotted as a function of the dimension of the damage index vector, that is, the number of features utilized. Each value in the plot is the average of all the rates resulted from the combinations that used the same number of features. The corresponding averages of false positives are superimposed. It can be seen that the selection of only five features provides a success rate nearly identical to the one obtained by considering all eleven features. The analysis presented in Figure 9 is associated with the detection of transverse defects by means of high frequency ultrasonic bandwidth. The time waveforms were recorded by the central transducer pair.

For the detection of the internal defects, it was found that the highest success rate was achieved with a high number of features. However, the number of false positives was also found to be high. This is probably related to the inclination of the transducers with respect to the rail surface. In preparation of the set up, the sensors position was optimized with respect to rail Section 1. However, as two AREMA sections were simultaneously tested, the sensitivity over rails 2 and 3 was not optimal. As such, the higher number of false positives may have been arisen.

It must be highlighted that the detection rate discussed in Figure 9 is not conceptually identical to the probability of detection (POD). For instance, let us assume that a given defect was probed at least five times during each test, and three out of five acquisitions were correctly identified as outliers. The success rate of the outlier analysis is $60 \%$. However, because the defect was identified at least once the probability of detection is $100 \%$.

\section{Field Test}

This section presents the results of field testing activities conducted over the past two years near Gettysburg, Pennsylvania. The site consisted of a segment of railway siding, $160 \mathrm{ft}(49 \mathrm{~m})$ in length, containing known defects. Several joints were present along the test section. Three, $1.8 \mathrm{~m}(6 \mathrm{ft})$ long, 136-lb A.R.E.M.A. sections with known internal defects in the head were inserted, and secured with joint bars, in the 


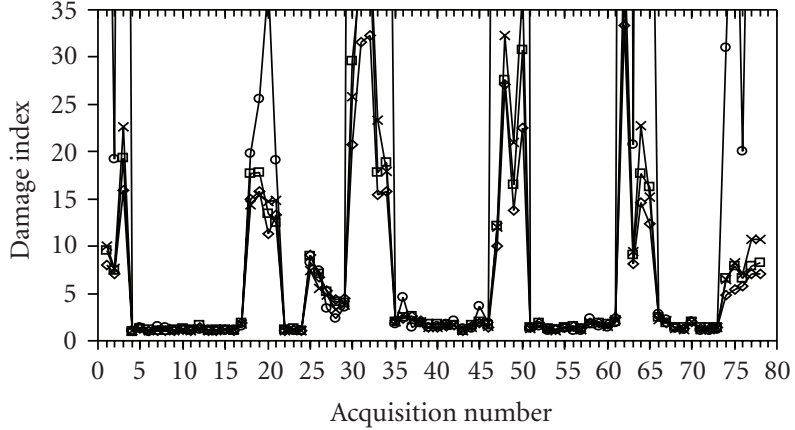

(a)

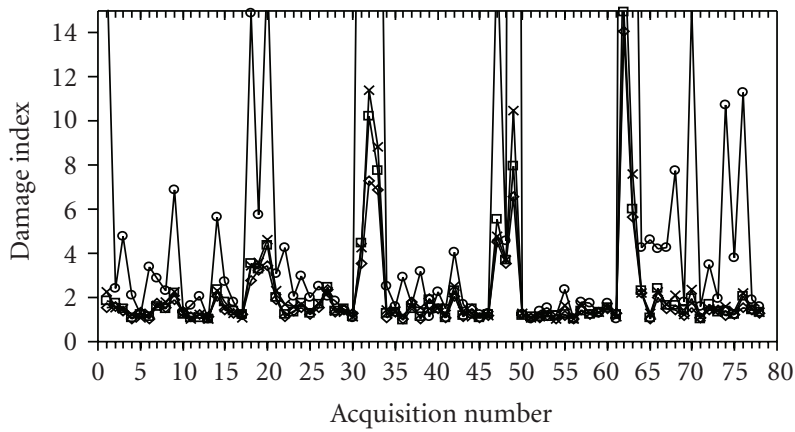

(c)

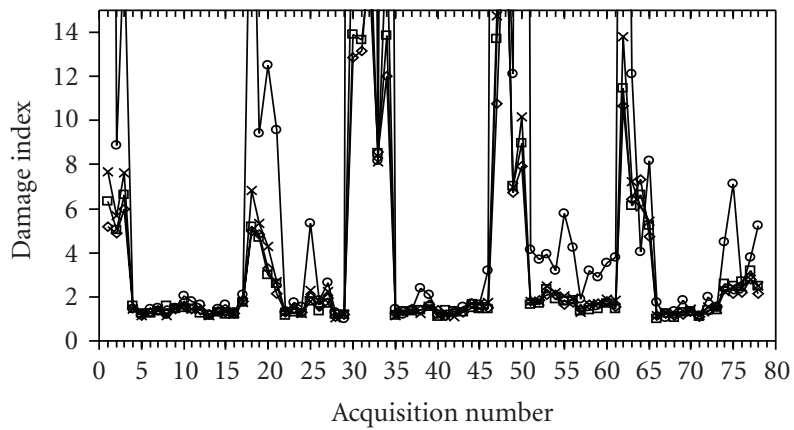

(b)

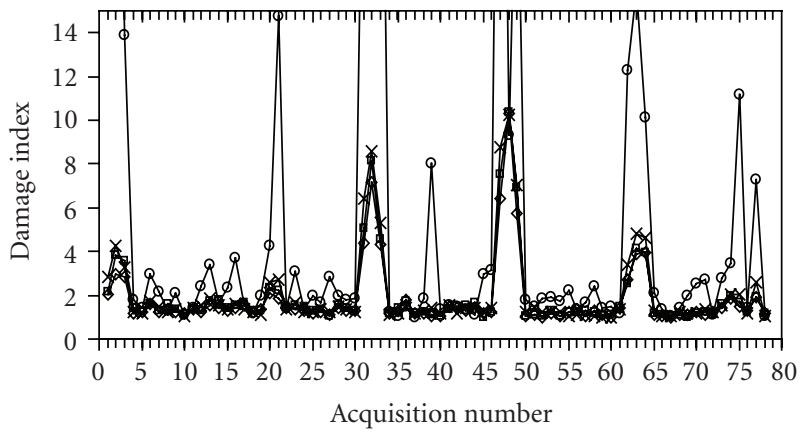

(d)

FIGURE 5: Test 1. Feature-based unidimensional damage index as a function of the acquisition number. The max amplitude (x), crest factor (o), peak-to-peak $(\square)$, and the RMS $(\diamond)$ of the wavelet coefficient vector are plotted for the (a) high frequency components and (b) low frequency components of the time waveforms acquired with the central pair transducers, and for the (c) high frequency components and (d) low frequency components of the time waveforms acquired with the gage side transducers.

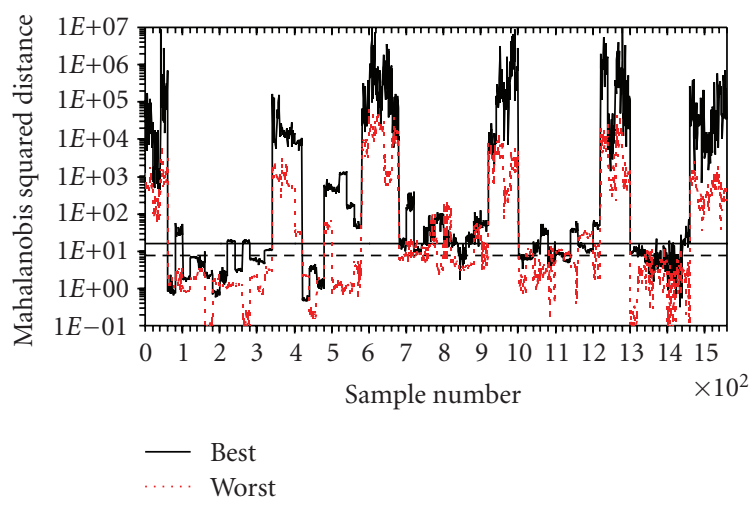

Figure 6: Test 1. Mahalanobis squared distance as a function of the sample number associated with the filtering combination that maximizes (best) and minimizes (worst) the detection of transverse surface defects probed using the central sensors pair and highfrequency bandwidth.

test section. From ultrasonic hand mapping, three internal defects were located and sized, with $3.5 \%$ head area (HA), $35 \% \mathrm{HA}$, and $12 \% \mathrm{HA}$, respectively. The hand mapping also indicated that all internal defects were primarily transverse, with two located in the gage side and one located in the head-center. In addition, two surface cuts were machined perpendicularly to the rail running direction, with sizes of
$5 \%$ and $2 \% \mathrm{HA}$, respectively. Two oblique surface cuts $(45$ degree inclination from the running direction) were also added at the top of the head, both about 3.5\% HA. A photo of the test site is shown in Figure 10(a). More details of the test site are in refs. [29, 30].

The prototype shown in Figure 10(b) was used for the test.

The signal processing algorithm implemented in the field test prototype was adapted to provide real-time indication of defects in a statistically robust manner and to provide two levels of classification. The first level identifies "discontinuities" in the track (including defects and joints); the second classification level flags each discontinuity as "joint," "surface defect," "internal defect," or "unclassified defect." The twolevel classification was implemented to minimize the chances of missing a defect (i.e., minimizing false negatives) and, at the same time, to provide the defect classification ("surface defect" versus "internal defect") whenever possible. Defects are flagged in real-time along with their position. The classification analyzes damage indexes. It must be pointed out that in the context of the field testing, the damage index is the Mahalanobis squared distance calculated by combining five statistical features associated with the time domain of the raw signals detected from air-coupled transducers pairs $[31,32]$.

Figure 11 shows a typical damage index plot as a function of the inspection distance. The largest peaks are rail joints 


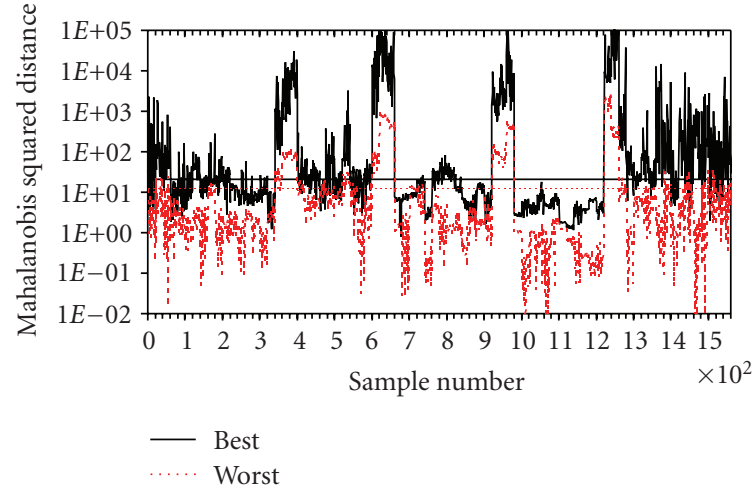

(a)

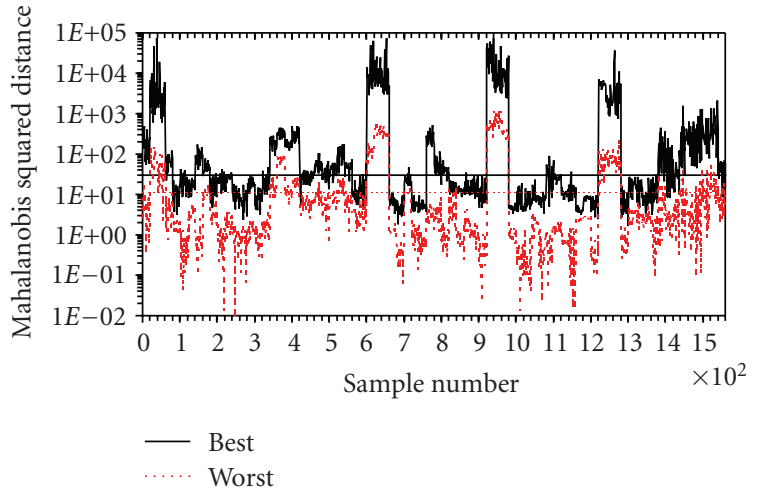

(b)

FIgURE 7: Test 1. Mahalanobis squared distance as a function of the sample number associated with the filtering combination that maximizes (best) and minimizes (worst) the detection of internal defects probed using (a) the gage sensors pair and high-frequency bandwidth and (b) the gage sensors pair and low-frequency bandwidth.

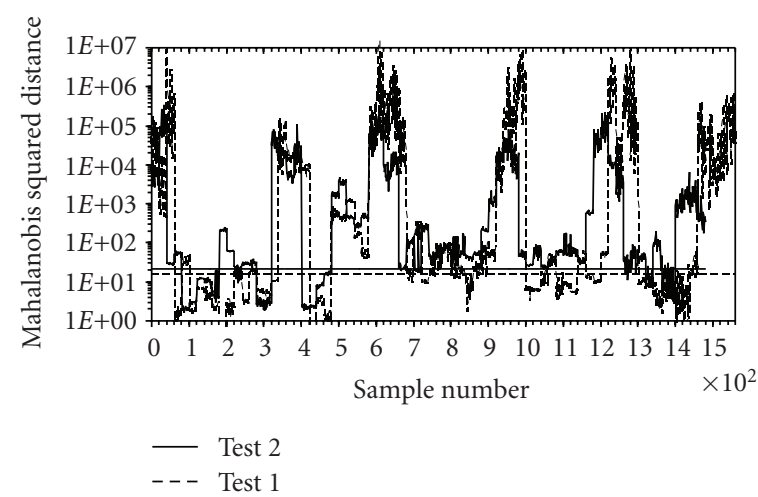

(a)

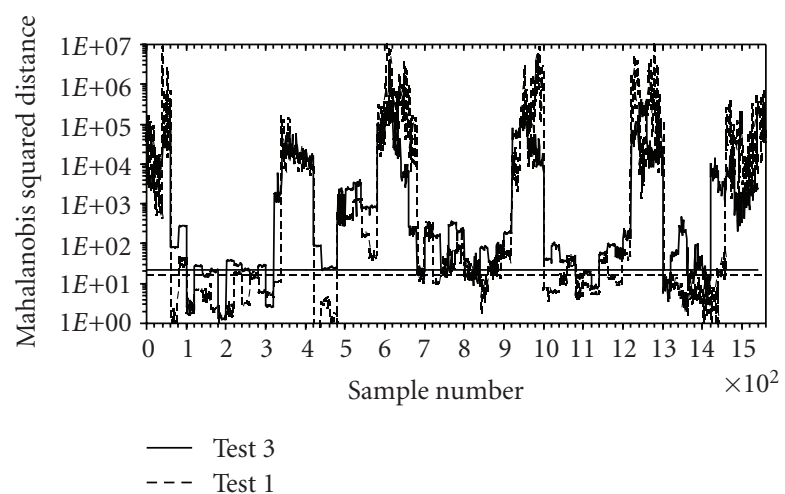

(b)

FIGURE 8: Mahalanobis squared distance as a function of the sample number associated with the filtering combination that maximizes (best) the detection of transverse surface defects probed using (a) the central sensors pair and high-frequency bandwidth during Test 1 and Test 2 , and (b) the central sensors pair and high-frequency bandwidth during Test 1 and Test 3.

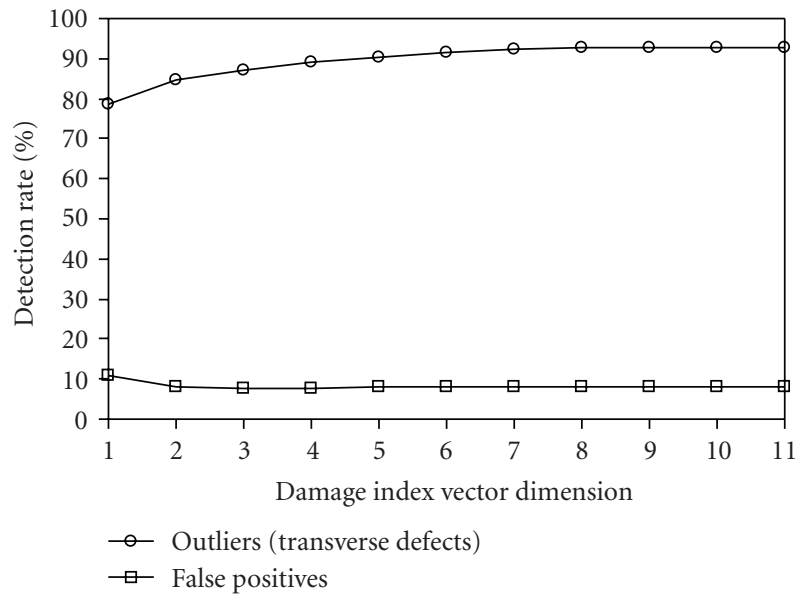

Figure 9: Average detection rate as a function of the dimension of the damage index vector as a result of probing transverse defects with central sensor pairs and high-frequency bandwidth in Test 1. which the system interprets as "very large discontinuity", and the smaller peaks are real defects. The discontinuity-free portions of the rail show an almost identically zero damage index.

Figure 12 shows the graphical user interface relative to the defect classification results. Notice that the plots are zoomed between locations $70 \mathrm{ft}$ and $120 \mathrm{ft}$. The software shows two plots, namely the "Discontinuities" plot which includes both joints and defects, and the "Classification" plot which color codes the discontinuities according to the classes "Joint," "Internal Defect," "Surface Defect," and "Unclassified Defect."

Various runs were made during four days of testing. Twenty-four of these runs were used to collect Damage Index data for estimating the POD for the present defects. The other runs were performed to collect raw data for further analysis. To assess the robustness of the system, the tests were performed under various conditions including calm versus 


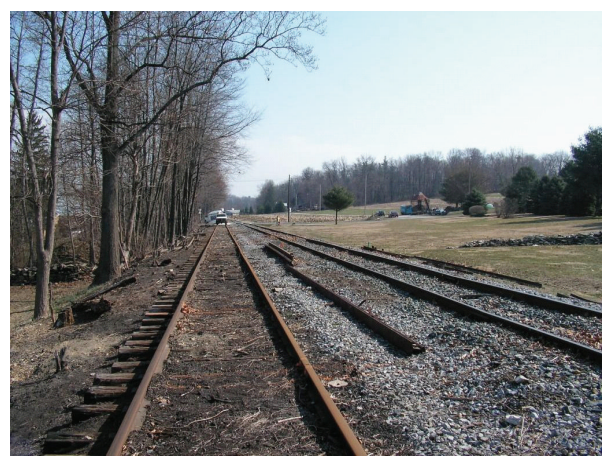

(a)

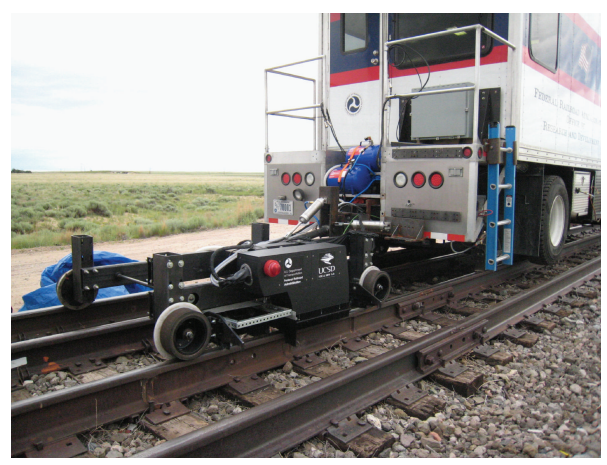

(b)

Figure 10: (a) Test site near Gettysburg, Pennsylvania. (b) Photo of the latest inspection prototype tested in the field.

TABle 4: Defect detection reliability during March 2008 field test at Gettysburg, PA.

\begin{tabular}{|c|c|c|c|c|c|c|c|c|}
\hline Defect & $\begin{array}{l}\text { Surface cut } \\
(5 \% \text { H.A })\end{array}$ & $\begin{array}{l}\text { Surface cut } \\
(2 \% \text { H.A })\end{array}$ & $\begin{array}{l}\text { Internal } \\
\text { defect } \\
\text { (gage side, } \\
\text { 3.6\% H.A.) }\end{array}$ & $\begin{array}{l}\text { Internal } \\
\text { defect } \\
\text { (gage side, } \\
\text { 35\% H.A.) }\end{array}$ & $\begin{array}{l}\text { Oblique cut } \\
(3.5 \% \text { H.A. })\end{array}$ & $\begin{array}{l}\text { Internal } \\
\text { defect } \\
\text { (center head, } \\
12 \% \text { H.A.) }\end{array}$ & $\begin{array}{l}\text { Oblique cut } \\
\text { (3.5\% H.A.) }\end{array}$ & \\
\hline $\begin{array}{l}\text { Position from } \\
\text { start }\end{array}$ & $81^{\prime} 7^{\prime \prime}$ & $82^{\prime} \_7.5^{\prime \prime}$ & $86^{\prime} 4^{\prime \prime}$ & $91^{\prime} \_3.5^{\prime \prime}$ & $95^{\prime} \_1^{\prime \prime}$ & $96^{\prime} 4^{\prime \prime}$ & $97^{\prime} \_8^{\prime \prime}$ & $\begin{array}{l}\text { False positive } \\
\%\end{array}$ \\
\hline POD (5 MPH) & 100 & 97.7 & 100 & 81.8 & 95.5 & 84.1 & 100 & 0.8 \\
\hline POD (10 MPH) & 100 & 100 & 100 & 100 & 75 & 87.5 & 100 & 2.9 \\
\hline $\begin{array}{l}\text { POD } \\
\text { (Cumulative) }\end{array}$ & 100 & 98.1 & 100 & 84.6 & 92.3 & 84.6 & 100 & 1.1 \\
\hline
\end{tabular}

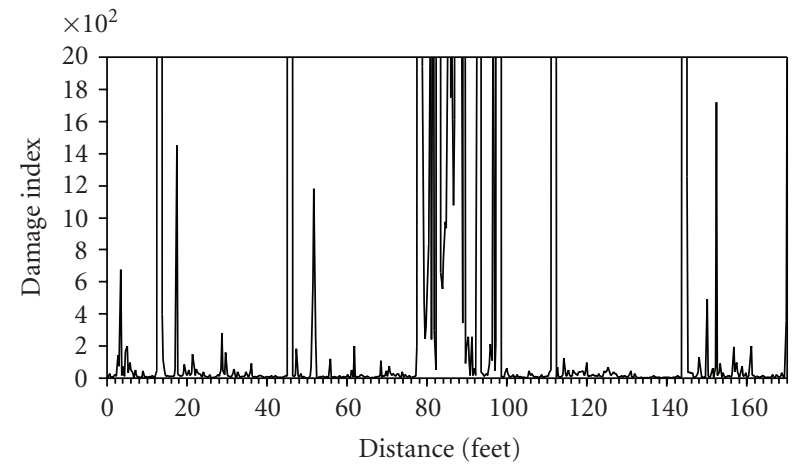

Figure 11: Field testing damage index as a function of the inspection distance. Large peaks denotes the presence of joints, smaller peaks denote the presence of defects.

windy, dry versus wet rail, $5 \mathrm{mph}$ versus $10 \mathrm{mph}$, and using two different powers of laser excitation.

The performance of the prototype, evaluated in terms of POD, is summarized in Table 4 . The results are shown separately for the $5 \mathrm{mph}$ and the $10 \mathrm{mph}$ testing speeds. The "cumulative" POD, obtained by considering all tests regardless of testing speed, is also shown. The POD was calculated as the ratio between the number of runs where a given defect was detected, over the total number of usable runs. A defect was considered detected when at least one of the statistical damage indices associated with the transducers' pair was activated. An index was called "activated" when the corresponding value was above a fixed threshold level. Table 4 shows an excellent performance in detecting all present defects. Particularly noteworthy is the high POD obtained for the three internal defects. The reliability of detection for the surface and the oblique cuts was also high. It is not clear why the POD of the 35\% H.A. internal defect was smaller than that of the other two internal defects at $5 \mathrm{mph}$. It is possible that the $35 \% \mathrm{H}$.A. defect has a curvature that makes the ultrasonic detection more challenging. The fact that this effect was not seen at $10 \mathrm{mph}$ could be due to the favorable position of the air-coupled sensors relative to the defect in the faster runs. Hence, for some of the defects, there seems to be a dependence of reliability of detection on the position of the sensors. This is not surprising, because the defect "ultrasonic shadow" footprint will change with position along the rail.

\section{Conclusions}

This paper describes a rail inspection prototype based on noncontact probing and ultrasonic guided waves coupled with a robust signal processing algorithm. The algorithm consists of discrete wavelet transform, feature extraction, and outlier analysis aimed at providing automatic damage detection and classification. The system uses laser generated guided waves to detect surface-breaking cracks and internal defects located in the rail head. Ultrasonic signals were detected by using three pairs of air-coupled transducers. Time waveforms were processed with the Discrete Wavelet 


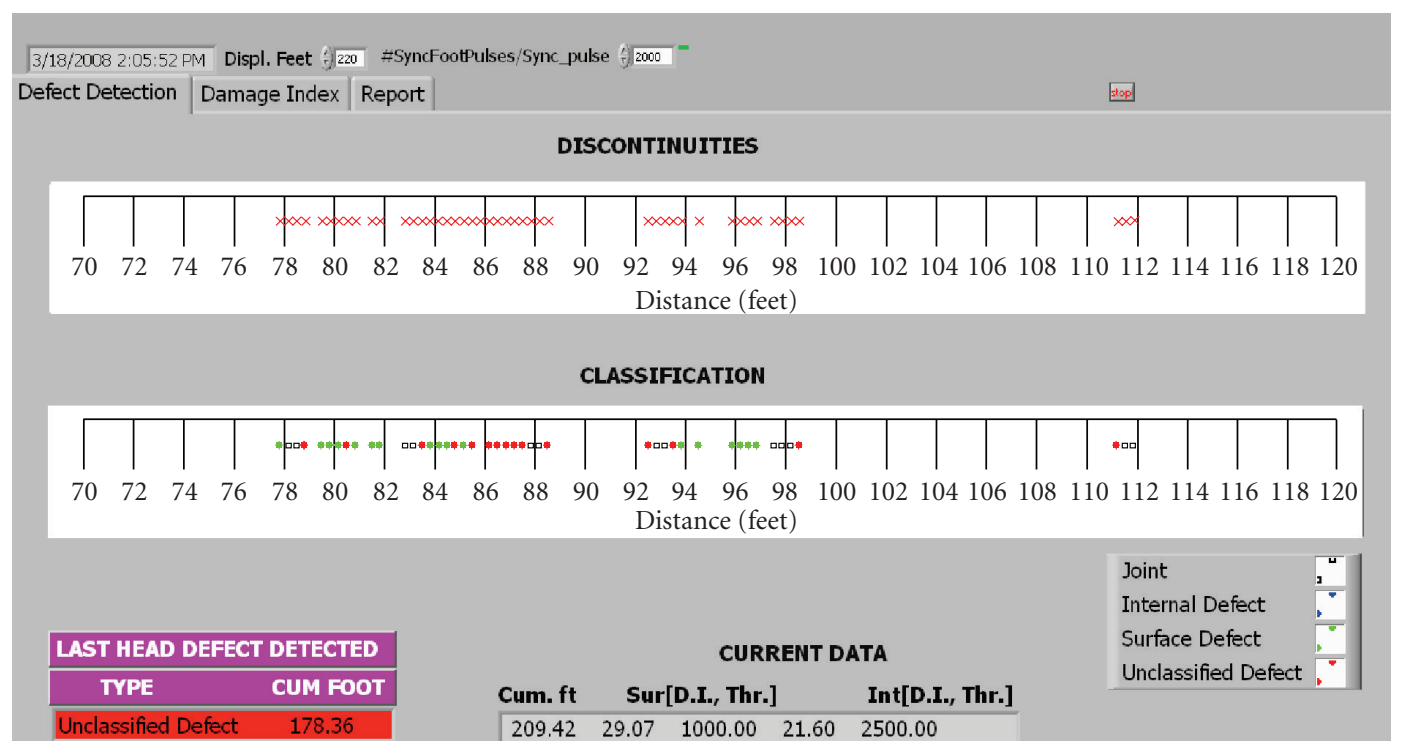

Figure 12: The "Defect Detection" window of the user's interface showing the real-time classification of joints and defects as color-coded points.

Transform to denoise the signals and to generate a set of relevant damage sensitive features used to construct a uni or multidimensional damage index. The damage index was fed to an unsupervised learning algorithm based on outlier analysis aimed at detecting anomalous conditions of the rail head. The population of data for the outlier analysis was created by adding digital random noise to the ultrasonic measurements. A total of 20 samples per acquisition were thus obtained for the baseline constituting the undamaged condition and for each of the damage conditions.

The importance of feature selection related to damage detection performance was examined. It was shown that combining multiple features in a multivariate analysis substantially improves the performance of the system in terms of sensitivity to defect sizes' detections and discrimination. By combining as few as five features, the improvement in defect detections was demonstrated. By separating the low-frequency from the high-frequency signal bandwidth, discrimination between internal and surface defects can be achieved. Moreover, by deploying sensors across the rail head width, the position of the defect within the head cross section can be identified.

The results presented here showed the effectiveness of deploying pairs of sensors over the entire rail width and the efficiency of performing robust signal processing to enhance the defect sensitivity of the inspection prototype. For instance, the oblique defect located was clearly identified through the analysis of the gage side data but barely visible through the analysis of the central transducers' data. The proposed setup, not only adds complete coverage of the rail head, but also offers a tool to conduct defect location and classification across the rail head section.

The last part of the paper presented the status of the rail defect detection prototype being developed at UCSD under FRA sponsorship. The prototype was field tested at speeds of up to $10 \mathrm{mph}$. The test track included three different sizes of Internal Head Defects (3.5\%, 35\% and 12\% H.A.), two sizes of transverse Surface Head Cuts (2\% and 5\% H.A.), and one size of oblique Surface Head Cut (3.5\% H.A.). The results of the tests indicated a high Probability of Detection for all defects present, ranging from $75 \%$ to $100 \%$ success rate over twenty-four runs conducted with varying environmental conditions including wind and rain. Unfortunately it was not possible to compare the proposed technology with existing rail inspection technologies. It is hoped that this comparison can be done in the near future.

\section{Acknowledgments}

This work, initially supported by the U.S. National Science Foundation through Grant no. CMS-84249, is being currently funded by the U.S. Federal Railroad Administration under Grant no. DTFR53-02-G-00011. The support of ENSCO, Inc. during the field tests is acknowledged and much appreciated. The authors are grateful to Mahmood Fateh, the FRA's Technical Representative, for his technical guidance, and to Gary Carr, former Senior Mechanical Engineer of ENSCO, and now FRA's Chief of Track Research Division, for providing technical and logistic support during the prototype assembling. M. Cammarata performed this research while visiting the University of Pittsburgh under a Study Abroad Fellowship (Decreto no 3684-2006) of the University of Palermo, Italy. Further support of the University of Pittsburgh to Mr. Cammarata through start up funding available to the first author is also acknowledged.

\section{References}

[1] Federal Railroad Administration, "Safety statistics data: 19922002,” U.S. Department of Transportation, 2002. 
[2] http://safetydata.fra.dot.gov/OfficeofSafety/.

[3] H. A. Toliyat, K. Abbaszadeh, M. M. Rahimian, and L. E. Olson, "Rail defect diagnosis using wavelet packet decomposition," IEEE Transactions on Industry Applications, vol. 39, no. 5, pp. 1454-1461, 2003.

[4] R. Clark, "Rail flaw detection: overview and needs for future developments," NDT and E International, vol. 37, no. 2, pp. 111-118, 2004.

[5] F. Lanza di Scalea, "Ultrasonic testing in the railroad industry," in Non-Destructive Testing Handbook, pp. 9-16, American Society for Nondestructive Testing, Columbus, Ohio, USA, 3rd edition, 2007.

[6] L. Oukhellou, P. Aknin, and J.-P. Perrin, "Dedicated sensor and classifier of rail head defects," Control Engineering Practice, vol. 7, no. 1, pp. 57-61, 1999.

[7] R. Pohl, A. Erhard, H.-J. Montag, H.-M. Thomas, and H. Wüstenberg, "NDT techniques for railroad wheel and gauge corner inspection," NDT and E International, vol. 37, no. 2, pp. 89-94, 2004.

[8] R. J. Greene, J. R. Yates, and E. A. Patterson, "Crack detection in rail using infrared methods," Optical Engineering, vol. 46, no. 5, Article ID 051013, 2007.

[9] P. Wilcox, M. Evans, B. Pavlakovic et al., "Guided wave testing of rail," Insight, vol. 45, no. 6, pp. 413-420, 2003.

[10] P. Cawley, M. J. S. Lowe, D. N. Alleyne, B. Pavlakovic, and P. Wilcox, "Practical long range guided wave testing: applications to pipes and rail," Materials Evaluation, vol. 61, no. 1, pp. 6674, 2003.

[11] D. Hesse and P. Cawley, "Surface wave modes in rails," Journal of the Acoustical Society of America, vol. 120, no. 2, pp. 733740,2006

[12] J. L. Rose, M. J. Avioli, P. Mudge, and R. Sanderson, "Guided wave inspection potential of defects in rail," NDT and E International, vol. 37, no. 2, pp. 153-161, 2004.

[13] J. L. Rose, M. J. Avioli, and W.-J. Song, "Application and potential of guided wave rail inspection," Insight, vol. 44, no. 6, pp. 353-358, 2002.

[14] J. D. McNamara, F. Lanza di Scalea, and M. Fateh, "Automatic defect classification in long-range ultrasonic rail inspection using a support vector machine-based 'smart system,' Insight, vol. 46, no. 6, pp. 331-337, 2004.

[15] I. Bartoli, F. Lanza di Scalea, M. Fateh, and E. Viola, "Modeling guided wave propagation with application to the long-range defect detection in railroad tracks," NDT and E International, vol. 38, no. 5, pp. 325-334, 2005.

[16] F. Lanza di Scalea, I. Bartoli, P. Rizzo, and M. Fateh, "Highspeed defect detection in rails by non-contact guided ultrasonic testing," Journal of the Transportation Research Board, vol. 1961, pp. 66-77, 2006.

[17] G. Alers, "Railroad rail flaw detection system based on electromagnetic acoustic transducers," Tech. Rep. DOT/FRA/ORD88/09, U.S. Department of Transportation, 1988.

[18] R. S. Edwards, S. Dixon, and X. Jian, "Characterisation of defects in the railhead using ultrasonic surface waves," NDT and E International, vol. 39, no. 6, pp. 468-475, 2006.

[19] S. Kenderian, D. Cerniglia, B. B. Djordjevic, G. Garcia, J. Sun, and M. Snell, "Rail track field testing using laser/air hybrid ultrasonic technique," Materials Evaluation, vol. 61, no. 10, pp. 1129-1133, 2003.

[20] T. Hayashi, W.-J. Song, and J. L. Rose, "Guided wave dispersion curves for a bar with an arbitrary cross-section, a rod and rail example," Ultrasonics, vol. 41, no. 3, pp. 175-183, 2003.

[21] J. McNamara and F. L. di Scalea, "Improvements in noncontact ultrasonic testing of rails by the discrete wavelet transform," Materials Evaluation, vol. 62, no. 3, pp. 365-372, 2004.

[22] F. L. di Scalea, P. Rizzo, S. Coccia et al., "Non-contact ultrasonic inspection of rails and signal processing for automatic defect detection and classification," Insight, vol. 47, no. 6, pp. 346-353, 2005.

[23] W. Staszewski, C. Boller, and G. Tomlinson, Health Monitoring of Aerospace Structures, John Wiley \& Sons, Munich, Germany, 2006.

[24] P. Rizzo and F. Lanza di Scalea, "Wavelet-based unsupervised and supervised learning algorithms for ultrasonic structural monitoring of waveguides," in Progress in Smart Materials and Structures Research, chapter 8, pp. 227-290, Nova Science, Hauppauge, NY, USA, 2007.

[25] P. Rizzo and F. L. di Scalea, "Wavelet-based feature extraction for automatic defect classification in strands by ultrasonic structural monitoring," Smart Structures and Systems, vol. 2, no. 3, pp. 253-274, 2007.

[26] P. Rizzo and F. L. di Scalea, "Ultrasonic inspection of multiwire steel strands with the aid of the wavelet transform," Smart Materials and Structures, vol. 14, no. 4, pp. 685-695, 2005.

[27] P. Rizzo, I. Bartoli, M. Cammarata, and S. Coccia, "Digital signal processing for rail monitoring by means of ultrasonic guided waves," Insight, vol. 49, no. 6, pp. 327-332, 2007.

[28] P. Rizzo, M. Cammarata, D. Dutta, H. Sohn, and K. A. Harries, "Unsupervised learning algorithm for fatigue crack detection in waveguides," Smart Materials and Structures, vol. 18, Article ID 025016, 11 pages, 2009.

[29] P. Rizzo, S. Coccia, I. Bartoli, and F. Lanza di Scalea, "On line high-speed rail defect detection-prototype assembling and field testing," Tech. Rep. SSRP-06/17, University of California, San Diego, Calif, USA, 2006.

[30] S. Coccia, I. Bartoli, F. Lanza di Scalea, and P. Rizzo, "Noncontact rail defect detection: first and second field tests," Tech. Rep. SSRP-07/15, University of California, San Diego, Calif, USA, 2007.

[31] S. Coccia, R. Phillips, I. Bartoli, S. Salamone, and F. Lanza di Scalea, "Non-contact rail defect detection," Tech. Rep. SSRP-08/02, Federal Railroad Administration, University of California, San Diego, Calif, USA, 2008.

[32] S. Coccia, I. Bartoli, R. Phillips, S. Salamone, and F. Lanza di Scalea, "Non-contact rail defect detection: fourth field test," Tech. Rep. SSRP-09/04, Federal Railroad Administration, University of California, San Diego, Calif, USA, 2009. 

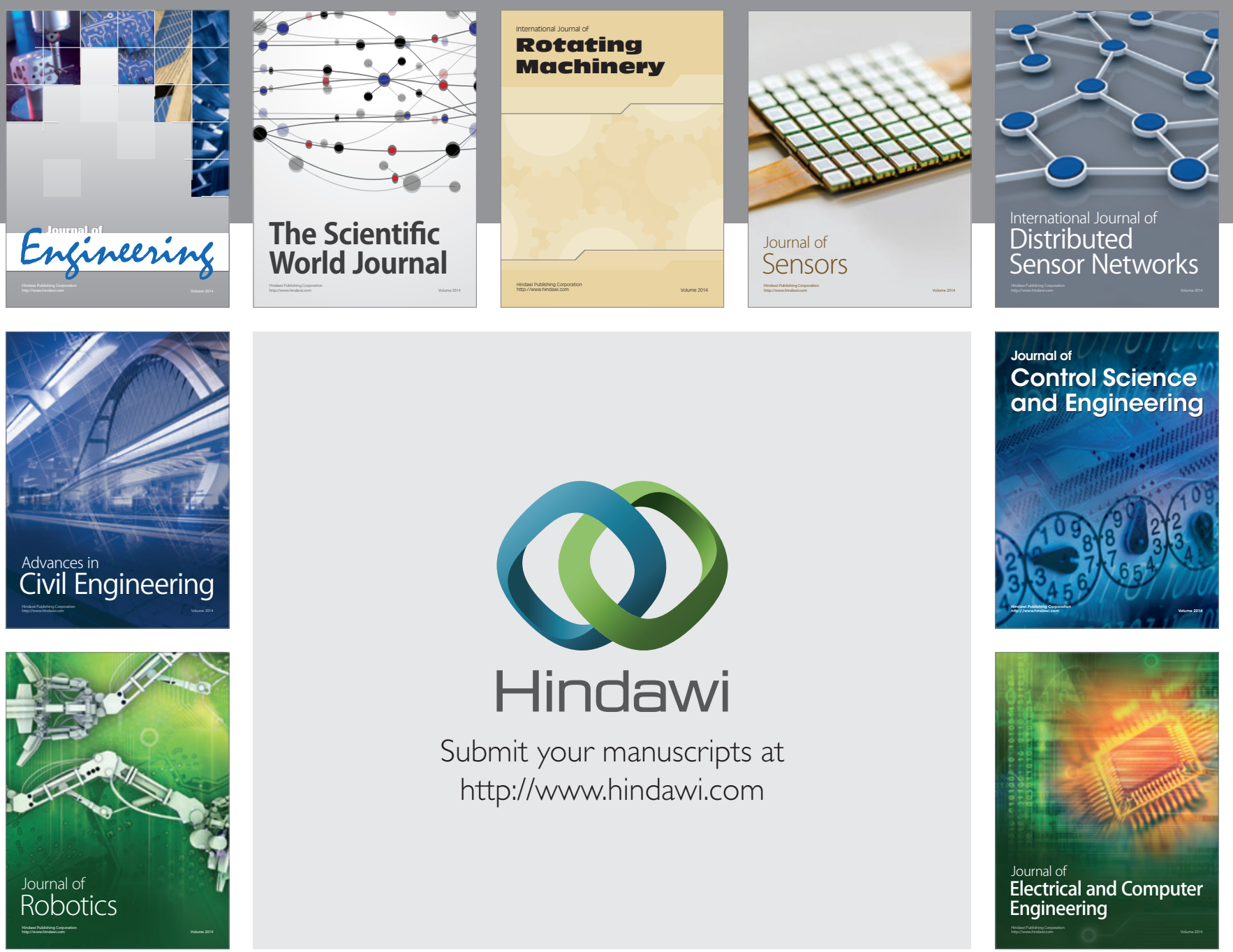

Submit your manuscripts at

http://www.hindawi.com
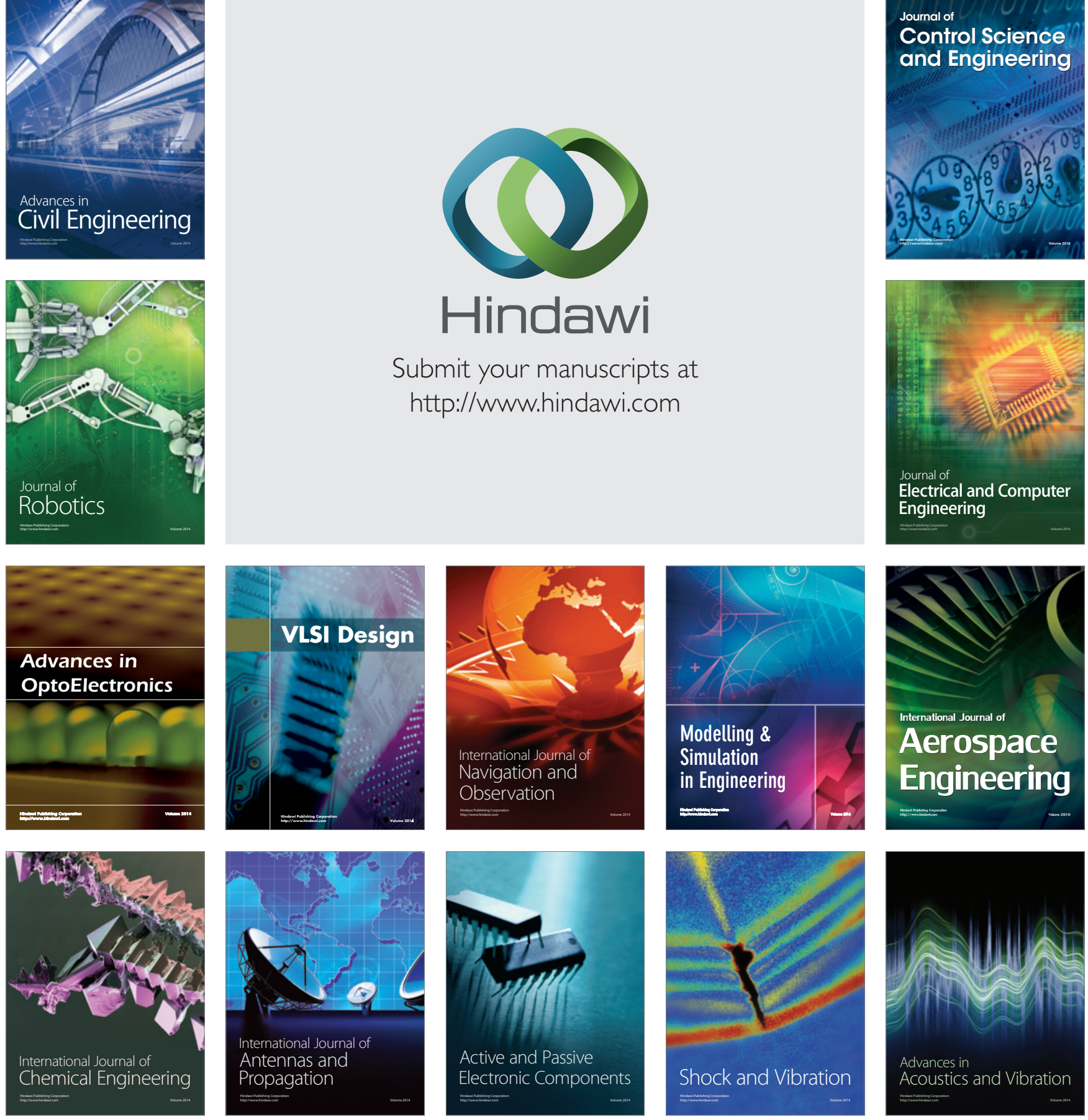